\title{
ALCALDES MAYORES Y SUBDELEGADOS FRENTE A LA SIEMBRA CLANDESTINA DE TABACO: PAPANTLA, 1765-1806
}

\author{
ALCALDES MAYORES AND SUBDELEGADOS COPING \\ WITH TOBACCO CLANDESTINE SOWING: PAPANTLA, \\ 1765-1806
}

\author{
Georgina Moreno Coello* \\ L’Ecole des Hautes Études en Sciences Sociales, París, Francia, <moreno.coello@gmail.com>
}

Resumen. Este trabajo tiene como objeto explorar las estrategias que permitieron la persistencia de la siembra clandestina de tabaco en Nueva España, en particular en la región de Papantla. Analizar las relaciones entre los alcaldes mayores, subdelegados y empleados del monopolio del tabaco, enfatizando la protección informal de la que gozó el cultivo ilegal de parte de las autoridades provinciales y examinar cuál pudo ser el destino del ahorro, así como de las ganancias obtenidas del tabaco ilegal, particularmente en el financiamiento de actividades comerciales y crediticias que llevaban a cabo alcaldes mayores y subdelegados, especialmente en el repartimiento de mercancías.

Palabras clave: monopolio, repartimiento de mercancías, economía de la tierra.

Abstract. This paper explores the strategies that allowed for a persistent clandestine tobacco sowing in New Spain, mainly in the region of Papantla. It analyzes the relationship between alcaldes mayores, subdelegados and employees of the tobacco monopoly, emphasizing the informal protection given to illegal sowings by provincial authorities. It also examines the potential allocation of savings and profits from illegal tobacco, mainly in the financing of commercial activities undertaken by alcaldes mayores and subdelegados, particularly for the repartimiento.

Key words: tobacco monopoly, clandestine sowing, repartimiento, land economics.

Fecha de recepción: enero de 2011. Fecha de aceptación: mayo de 2011.

* Agradezco profundamente las atinadas observaciones realizadas por los dictaminadores anónimos que evaluaron el presente artículo.

Am. Lat. Hist. Econ., año 19, núm. 3, septiembre-diciembre, 2012, pp. 206-234 


\section{INTRODUCCIÓN}

partir de la caída de La Habana y Manila en manos de los ingleses
en 1762, la corona española se vio obligada a modernizar el sistema
defensivo colonial, lo que acrecentó la demanda de recursos y la necesidad de hacer una revisión integral del sistema fiscal con el objeto de encontrar nuevas fuentes de financiamiento que le permitieran hacer frente a sus crecientes compromisos. ${ }^{1}$ En ese marco resurgió el proyecto de crear en Nueva España un monopolio estatal del tabaco, cuya explotación quedaría reservada a la corona. Dado el extenso consumo existente en Nueva España, se esperaba recaudar rápidamente cuantiosos recursos. En efecto, los resultados superaron ampliamente las expectativas y el ramo del tabaco se convirtió pronto en la segunda fuente de ingresos más importante del reino, superado sólo por la minería.

La importancia económica que alcanzó el nuevo monopolio ha marcado la orientación de las investigaciones hechas al respecto, privilegiándose el estudio de la producción y el comercio legal de la hoja, su funcionamiento y rentabilidad, dejando de lado las implicaciones y los problemas suscitados por la siembra ilegal. El establecimiento del monopolio dio lugar a siembras clandestinas y a la aparición de redes de interés que favorecieron el cultivo de la hoja. Sin embargo, dado el evidente carácter ilegal, el estudio de la siembra ilícita y el contrabando presenta dificultades, a lo que se añade la singularidad de su represión a cargo de la Real Renta del Tabaco, que entró en competencia con las funciones judiciales desempeñadas por los alcaldes mayores y subdelegados. En este trabajo nos interesamos en analizar la siembra ilegal de tabaco y en particular la articulación de las relaciones e intereses que se establecieron entre los sembradores clandestinos y las autoridades provinciales y locales, en el marco de las políticas represivas adoptadas por el monopolio contra la producción ilegal. El interés se derivó de la persistencia observada en las siembras ilegales en la jurisdicción de Papantla, a pesar de la incesante persecución.

La siembra del tabaco fue criminalizada con la aparición del monopolio, convirtiéndola en un acto delictivo, pero en los hábitos y en la organización de la producción local, la prohibición fue para los pueblos un acto autoritario que trastocaba el orden tradicional, y los contraventores no se sintieron obligados a acatarla y en ocasiones tampoco las autoridades locales. Aquí la distinción normativa entre delito y oposición, o entre legalidad, legitimidad y justicia, se volvió confusa, criminalizando una actividad realizada desde "siempre" y cuya justicia era difícil demostrar a los infractores, quienes se mostraron reacios a abandonar una práctica propia,

${ }^{1}$ Klein, "Economía”, 1985, pp. 561-609. 
realizada desde tiempos inmemoriales y cuya reciente ilegalidad no discutían, pero cuya justicia, legitimidad y pertinencia se negaban a aceptar. De alguna manera los habitantes de toda la región aplicaron el recurso "obedézcase pero no se cumpla". Cuando se interrogaba a los contraventores si conocían las razones de la prohibición, alguno respondió, "porque el rey no quería", lo cual debió ser difícil de aceptar como una razón suficiente para someterse a la voluntad real, por lo que el incumplimiento a la norma fue la regla.

Las reformas borbónicas introdujeron una serie de transformaciones dentro del marco administrativo colonial. Sin embargo, muchos de los que debían encargarse de aplicar las nuevas ordenanzas fueron los mismos que habían ocupado los puestos anteriores, transitando de las alcaldías mayores a las subdelegaciones, por lo que fue común hallar resistencias al abandono de privilegios relacionados con el cargo. Además, los nuevos funcionarios que ocuparon los puestos después de la reforma y donde las viejas prerrogativas tenían un gran atractivo, tampoco se distinguieron por un acatamiento intransigente de las ordenanzas, contentándose con un ejercicio flexible de la normatividad tradicional, adaptándola al nuevo contexto legal.

La siembra ilegal del tabaco es un indicador del sentimiento general de los indios hacia las políticas y decisiones tomadas por las autoridades coloniales cuando eran percibidas como injustas, como en la prohibición de la siembra de tabaco, a cuyos beneficios los indios no se resignaron a renunciar, a pesar de haber transcurrido muchos años desde el establecimiento de la Real Renta. La persistencia de la práctica sugiere que aun bajo la amenaza de la represión, la siembra de tabaco seguía siendo considerada "justa y legítima" por los campesinos, a pesar de aceptar la ilegalidad de su práctica.

\section{CRIMEN Y CASTIGO: NORMATIVIDAD Y REPRESIÓN EN TIEMPOS DEL MONOPOLIO}

Pocos años después de la llegada de Carlos IV al trono español, se impulsó la idea de establecer el monopolio estatal del tabaco en Nueva España. La guerra contra Inglaterra precipitó los acontecimientos y se hizo más apremiante la necesidad de encontrar nuevos y mayores recursos para financiar la defensa de los reinos españoles en América, presentándose para ello propuestas que exponían las ventajas que aportaría un monopolio en Nueva España. Inspirándose en las experiencias favorables realizadas en 
Cuba, Perú y Buenos Aires, se propuso iniciar el estanco novohispano monopolizando un segmento del comercio del tabaco. ${ }^{2}$

Las primeras medidas adoptadas para el establecimiento del monopolio se vieron reforzadas con la llegada al reino de Jacinto Díez de Espinosa, primer director de la Real Renta del tabaco, quien traía consigo las instrucciones para el establecimiento del estanco en Nueva España. El bando que creó el monopolio real sobre la hoja fue publicado el 11 de diciembre de 1764 y con él se inició el periodo conocido como el de las reformas borbónicas. Durante el año de 1765 se comenzaron a ejecutar las órdenes contenidas en las instrucciones, que comprendían la prohibición del cultivo y el control de la venta del tabaco. El establecimiento del estanco fue favorecido y acelerado por la intervención del visitador José de Gálvez, quien logró vencer todos los inconvenientes previstos por el virrey y Díez de Espinosa, quienes, temerosos de la reacción popular, se oponían a establecer el estanco fuera del arzobispado de México y sobre todo, desaprobaban la creación de fábricas de puros y cigarros por cuenta del rey.

Se ordenó la extinción gradual de todo cultivo en Nueva España, salvo en ciertas jurisdicciones, cuya demarcación al final se limitó a las villas de Córdoba, Orizaba y los pueblos de Huatusco y Zongolica. En todo el resto del reino quedaba terminantemente prohibida la siembra de tabaco. ${ }^{3}$ Pronto se revelaron las grandes ganancias que el estanco podía aportar al tesoro real, convirtiéndose paulatinamente en el segundo rubro de ingresos fiscales más importante, superado sólo por los ingresos procedentes de la plata. Para fines del siglo XVIII el monopolio contribuía con ingresos superiores a los 3000000 de pesos anuales. ${ }^{4}$

La producción de tabaco y su comercio ilegal dieron lugar a una normatividad que comenzó a aplicarse encargando a los gobernadores, alcaldes mayores y demás autoridades locales destruir las siembras clandestinas o silvestres, ordenándoles evitar la introducción del tabaco ilegal a los pueblos. Se promulgaron bandos que marcaban las penas a las que se harían acreedores aquellos que incurriesen en esos delitos: para los contrabandistas decomiso y pérdida del tabaco, embargo de caballerías, carruajes, bagajes y pago del duplo del valor y costos de la causa. A los productores se les cobraría igualmente el doble del valor del tabaco, costos de la causa y la confiscación de las tierras.

Para combatir la siembra ilegal y el contrabando, la Renta estableció una especie de policía especializada, dedicada exclusivamente a la per-

\footnotetext{
${ }^{2}$ Rivera y Castro, "Real", 1988, p. 107.

${ }^{3}$ Ibid., p. 117.

${ }^{4}$ Marichal, Bancarrota, 1999, pp. 76-77; Deans-Smith, "Estanco", 1999, p. 84, y González, Tabaco, 2002, p. 62.
} 
secución de la producción y comercio de tabaco ilegal, conocida como resguardo. En febrero de 1767 se creó el primer resguardo encargado de vigilar el casco de la ciudad de México y la jurisdicción de su arzobispado. ${ }^{5}$ El mismo sistema se extendió después a todas las administraciones, cuyos fielatos tuvieron a cargo la inspección y el combate de la producción y comercio ilegal. Los visitadores, guardas, cabos y guardas patricios formaban el resguardo y eran responsables de perseguir a los contraventores, levantar un proceso sumario y, en su caso, aplicar el castigo correspondiente. El resguardo organizó visitas anuales, principalmente a los lugares susceptibles de realizar siembras clandestinas a fin de que esas fueran destruidas y los responsables castigados. La Renta dividió administrativamente el reino en factorías, cada una de las cuales incluía una fábrica, de cuya producción se abastecieron tercenas, fielatos y estanquillos de la jurisdicción. Cada fielato estaba encabezado por un fiel de la Renta, que tenía bajo su control un resguardo. A diferencia de otros oficiales reales, los empleados de la Renta gozaban de un salario anual y, además, los visitadores recibían una gratificación por el volumen que lograran confiscar.

A pesar del sistema represivo que se estableció y los crecientes castigos que amenazaron a contrabandistas y productores, el tráfico ilegal no desapareció. Durante la década de 1770 se publicaron diversos bandos que reforzaban las sanciones contempladas en las instrucciones de 1764, llegando a incluir penas corporales. ${ }^{6}$ Sin embargo, los indios estuvieron exentos de la mayoría de las penas señaladas a los infractores y las sanciones que les aplicaron fueron menos severas, limitándose a quince días de prisión y 30 días, si eran reincidentes.

Los bandos buscaban reforzar la persecución al contrabando e impedir las siembras clandestinas, para lo cual se reiteró el mandato que implicaba a gobernadores, corregidores, alcaldes mayores, así como a sus respectivos tenientes, a fin de incitarlos a perseguir a los responsables de fraude, pues hasta entonces se había observado "una culpable omisión y tolerancia" hacia ese delito. A pesar del creciente rigor de la legislación adoptada no se logró impedir que continuara la producción y venta clandestina de tabaco. ${ }^{7}$ Sin embargo, la producción ilegal no podía prosperar sin la protección de los alcaldes mayores, cuya complicidad se advirtió en 1778, dado el abierto descuido que mostraban en la persecución del cultivo ilegal en muchas jurisdicciones, entre las cuales encontramos Teziutlán,

\footnotetext{
${ }^{5}$ Rivera y Castro, "Real", 1988, p. 114.

${ }^{6}$ Ibid., p. 115.

7 Archivo General de la Nación (en adelante AGN), Tabaco, vol. 197, y González, Tabaco, 2002, p. 51.
} 
Tetela y Xonotla, Tulancingo, Huauchinango, Huayacocotla y Papantla. ${ }^{8}$ Cuando los alcaldes mayores fueron interrogados sobre la evidente impunidad que gozaban los contraventores, respondieron que esos cultivos permitían a los indígenas pagar sus obligaciones tributarias, sugiriendo así que el primer beneficiado de las plantaciones ilegales era el propio rey. ${ }^{9}$ En 1783, a la llegada del virrey Matías de Gálvez a Nueva España, se reavivó la lucha contra las siembras y el comercio ilegal del tabaco; diversos bandos fueron publicados al respecto, donde se advirtió la persistencia del fraude en Huauchinango, Zacatlán de las Manzanas, Tetela, Teziutlán y Papantla.

Los bandos ordenaban una mayor implicación de los alcaldes mayores en la persecución de las siembras clandestinas, lo cual indica que hasta entonces había continuado la tolerancia por la indiferencia que mostraron esas autoridades. ${ }^{10}$

En Nueva España se han podido detectar dos regiones importantes de siembra clandestina, una de las cuales se situó al norte de las intendencias de Veracruz, México y Puebla, conformada por las jurisdicciones de Tulancingo, Huayacocotla, Huauchinango, Zacatlán y Papantla, destacando particularmente Papantla, tanto por la persistencia del fraude, como por la notable complicidad descubierta entre los contraventores y las autoridades locales y provinciales. ${ }^{11} \mathrm{La}$ amplia región situada entre la sierra, las estribaciones montañosas y las llanuras que descienden hasta las costas del Golfo de México, había sido también una de las zonas de producción tabacalera desde la época precolombina, reconocida también por la calidad de su tabaco; además, se hallaba situada en una posición estratégica, vinculando una vasta red comercial que incluía el valle de Tulancingo, la sierra alta y baja de Zacatlán y las llanuras de Papantla, con acceso al comercio de cabotaje, que sirvió también a todo tipo de comercio, legal e ilegal.

En 1780 el contador de la Real Renta del Tabaco, Silvestre Díaz de la Vega, quien será después director general de la misma, señalaba la particular implicación de esa región en el contrabando de tabaco, sobre todo las

${ }^{8}$ El resto de las jurisdicciones eran Acayucan, Acatlán, Antigua, Autlán, Cosamaloapan, Colima, Huejutla, León, Meztitlán, Nexapa, Nuevo Santander, Nochistlán, San Sebastián de Sonora, San Juan de los Llanos, Temascaltepec, Teutila, Tehuacán de las Granadas, Tetela del Río, Tampico, Tepic y Compostela, Villa de Valles, Villa Alta, Xalapa, Xicayán, Yohualica, isla del Carmen y Zapotlán. Rivera y Castro, "Real”, 1988, pp. 120-121.

${ }^{9}$ Deans-Smith, Bureaucrats, 1992, p. 31.

${ }^{10}$ AGN, Alcaldes mayores, vol. 7, fs. 123-124, 265-267, y vol. 9, fs. 88-88v, 223-224.

${ }^{11}$ AGN, Tabaco, Inventario general, y McWatters, "Royal", 1979, pp. 71-72, nota 58. La segunda región se sitúa al sur de la intendencia de México, en una zona que comprendió las jurisdicciones de Tixtla, sierra de Zeutla, Chilpancingo, Tetela del Río, Apatzingán y Cutzamala. 
jurisdicciones de Teziutlán, Atzatlán, Altotonga, Tlapacoya, Jalapa, Coatepec, Huauchinango, Zacatlán y Papantla. ${ }^{12}$

\section{PAPANTLA ¿UN MODELO PARA LA CONSERVACIÓN Y DEFENSA DEL CULTIVO DE TABACO?}

Cuando en 1767 los indios de Papantla se amotinaron contra el alcalde mayor se evidenciaron los abusos que ese cometía contra los indios: un repartimiento excesivo, servicios personales inmoderados y un rigor extremo en los castigos. Sorprendentemente, la causa del motín fue sólo contra la severidad excesiva del magistrado, eludiéndose todo el resto de las arbitrariedades que ni siquiera figuraron en el proceso. De manera inexplicable el silencio se extendió también a la prohibición de siembras de tabaco, contra la cual los indios no expresaron queja alguna, a pesar del insistente cuestionamiento que hicieron las autoridades al respecto. ${ }^{13}$ Contrariamente a lo sucedido en 1765, cuando en Papantla la oposición a la Renta se manifestó violentamente en un incendio que acabó con todo el tabaco reunido por el alcalde mayor y con las casas reales, sucediendo lo mismo al siguiente año con la casa del teniente de Misantla, ${ }^{14}$ en 1767 la cuestión del tabaco ya no causaba ningún conflicto y los papantlecos, que tenían una conocida reputación de pueblo difícil, habían abandonado toda oposición al monopolio, aceptando las prohibiciones que imponía la Renta. ${ }^{15}$ Sin embargo, esto no deja de ser desconcertante, cuando sabemos que el reparto abusivo fue una de las causas más frecuentes de los motines, ${ }^{16}$ además de lo que sucedía en otros puntos de Nueva España, donde en 1767 la oposición al monopolio surgía espontáneamente, aun por causas que nada tenían que ver con la Renta. Los habitantes de Guanajuato, Pátz-

\footnotetext{
12 AGN, Renta del Tabaco, vol. 3, fs. 70-86. Véanse McWatters, "Royal”, 1979, p. 175, nota 11; AGN, Tabaco, Inventario general, y Deans-Smith, Bureaucrats, 1992, p. 31.

${ }^{13}$ AGN, Criminal, vol. 304. El motín se desató por el traslado del indio Nicolás Olmos, cuya prisión fue considerada particularmente injusta y sobre todo cuando corrió el rumor de que el prisionero iba a ser vendido a un obraje, como se aseguró que ya había sucedido a otros indios del lugar.

${ }_{14}$ Ibid., exp. 2, f. 92v, y Rivera y Castro, "Real", 1988, p. 112. A fines de 1765 se registró en la ciudad de Puebla una fuerte oposición al establecimiento de una fábrica de puros y cigarros a cargo de la Renta del Tabaco. Una mañana aparecieron muros pintados con leyendas que decían "muera el rey de España y viva el inglés" o "muera España”. Deans-Smith, Bureaucrats, 1992, p. 21, y McWatters, "Royal”, 1979, pp. 39-40.

${ }^{15}$ Ducey, "Village", 1999, p. 463. Antonio Escobar señala que entre 1750 y 1820 ocurrieron en las Huastecas quince motines, es decir, brotes de violencia de corta duración, de los cuales ocurrieron casi la mitad, siete, en Papantla entre 1762 y 1786, lo que significa que era una región de alta conflictividad y cuya población se sublevaba fácilmente, a fin de manifestar su oposición a las medidas que los afectaban. Escobar, "Dirigencias", 2002, p. 221.

${ }^{16}$ Pastor, "Repartimiento", 1985, p. 213.
} 
cuaro y Uruapan, al oponerse a la leva, exigieron al mismo tiempo que desapareciera el estanco del tabaco. En Uruapan los mulatos gritaban con vehemencia "imuera el rey, mueran los gachupines y muera el estanquero, que no queremos estancos ni milicias!" ${ }^{17}$ Las reivindicaciones que a gritos hacían los mulatos de Uruapan, muestran bien el gran descontento provocado por el estanco, pero en Papantla nada. Admitiendo que así hubiera sido, es difícil creer que los indios de Papantla hubieran cedido con tal resignación ante los abusos del alcalde mayor, por lo que creemos que el silencio que guardaron al respecto ocultaba algo más y la siembra de tabaco participaba en ello. De los hechos se deduce que la prohibición de la siembra de tabaco estaba siendo usada como moneda de cambio en la relación de reciprocidad entre los indios y el alcalde mayor, quien estaba aprovechando al máximo los nuevos términos del acuerdo que le proporcionaba la cuestión de la interdicción del tabaco. El motín reveló la existencia de un repartimiento confiscatorio del comercio local extremamente coercitivo, que obligaba a todos los habitantes a comprar una mula al año o su equivalente en otros productos y aunque el precio no era en términos absolutos descomunal, 32 pesos, aplicado individualmente era exorbitante, sin embargo, nadie se rebeló por ello. ${ }^{18}$ Lo excesivo del repartimiento nos indica también los altos excedentes que se podían extraer de esa región, dados los numerosos y variados recursos existentes: vainilla, cera, chicle, piloncillo, pimienta gorda, maderas tropicales, pesca considerable y abundante maíz (proveniente de dos cosechas anuales), ${ }^{19}$ de ahí las ganancias extraordinarias que esperaba obtener el alcalde mayor; pero es asombrosa la serenidad con la que aceptaron los indios la rapacería del oficial real. Creemos que la imperturbabilidad mostrada por los papantlecos se explica por los términos en que se construyó el nuevo pacto, que incluyó la tolerancia hacia las siembras clandestinas de tabaco, pues como nos indica Arij Ouweneel, los alcaldes mayores tenían que acomodarse a los deseos de los indios, pues los oficiales reales tampoco disponían de los medios para forzarlos a aceptar cualquier cosa de repartimiento y los indios sabían cuando un repartimiento era excesivo e incluso ilegal. ${ }^{20} \mathrm{La}$ explicación que dieron los indios a su mutismo es tan inverosímil que evidentemente escondía algo más. Los ciclos de la producción de maíz, vai-

${ }^{17}$ Castro, Nueva, 1996, pp. 166-168.

${ }^{18}$ Una mula por 32 pesos es el precio máximo que registra Margarita Menegus en Repartimiento, 2000, pp. 9-64. En general los repartimientos no se hacían de manera individual, sino que se calculaban de acuerdo con el volumen de manufacturas, ganado o dinero que se podía repartir en un pueblo tomando en cuenta los ingresos de la comunidad en su conjunto, calculados a partir del tributo.

${ }^{19}$ Villaseñor, Theatro, 1746, pp. 318-319, y Kourí, Pueblo, 2004, p. 75.

${ }^{20}$ Ouweneel, “Gobernador", 2000, pp. 68 y 70. 
nilla y tabaco estaban estrechamente ligados y es indudable que el alcalde mayor no tenía el menor interés en provocar perturbaciones que causaran la disminución de productos que abastecían el repartimiento. ${ }^{21}$ Cera, vainilla, maíz y piloncillo debieron ser los principales productos con los que se pagaban las mulas de repartimiento aludidas en el conflicto de 1767, como sucedía en las provincias aledañas de la bocasierra, donde el volumen de repartimiento de mulas alcanzó casi 30\% del total en lo que será la intendencia de Puebla. ${ }^{22} \mathrm{El}$ tabaco, además de ser una fuente de recursos económicos, cuya ganancia o ahorro debió servir para pagar los productos de repartimiento, era también uno de los pilares en los que se asentaba la producción de los más rentables cultivos locales y en los que descansaban poderosos intereses ligados al alcalde mayor. Además, la prohibición de la siembra de tabaco debió ser muy provechosa para los alcaldes mayores, pues les ofreció un argumento de peso para imponer, a cambio de su tolerancia, repartos excesivos, y los indios no tuvieron más que aceptarlo si querían seguir sembrando tabaco. Todo esto se vería confirmado 20 años después, cuando reaparecieron protestas contra la destrucción del tabaco, lo que prueba que las autoridades de Papantla poco hicieron para reprimir las siembras en los años que median entre el establecimiento del estanco y la década de 1780, cuando se reactivó la lucha contra la siembra clandestina y por razones comerciales, ajenas a los intereses de la Renta del Tabaco, las tierras donde se sembraba el tabaco ilegal despertaron la codicia de las autoridades locales, rompiendo el acuerdo entre los indios y el alcalde mayor.

\section{LA DISPUTA DE LA VAINILLA LEGAL CONTRA EL TABACO ILEGAL}

Francisco de Zamitis, visitador de la Real Renta del Tabaco de Zacapoaxtla, recordó la gran dificultad que enfrentó en 1785 debido al tumulto que se había registrado ese año en Papantla, obligándolo a mantener reunidos en una sola partida a todos los miembros del resguardo destinados a las tres visitas, por el temor que provocaba "la indiada", que se hallaba sublevada en los montes. Sólo se pudieron encontrar los troncos secos de las matas de tabaco que ya habían sido cosechadas, habiendo sido imposible incautar una sola arroba de la hoja, ni arrestar a nadie, ${ }^{23}$ lo que demues-

${ }^{21}$ Kourí, Pueblo, 2004, pp. 80-85, y Velázquez, Cuando, 1995, p. 125.

${ }^{22}$ Zacatlán, Huauchinango, Huayacocotla, Teziutlán y Tetela reunían, según Pietschmann, $30 \%$ del total del repartimiento de mulas de la intendencia de Puebla. Pietschmann, Mexiko, 2000, pp. 116-117.

${ }^{23}$ AGN, Tabaco, vol. 114. 
tra que los indios habían seguido efectuando sus siembras sin mayores contratiempos.

El año de 1785 no terminó sin sobresaltos. A finales de ese año el resguardo enfrentó nuevamente la irritación de los habitantes de Papantla que se oponían a cualquier diligencia del estanco, desatando un alboroto cuando los empleados de la Renta pretendían proceder al registro de casas en búsqueda de tabaco. En el mes de noviembre los guardas de Papantla iniciaron una ronda y cuando los indios se percataron de la presencia de aquellos, comenzaron a dar voces, por lo que los empleados del monopolio se vieron obligados a retirarse sin poder cumplir su comisión. Este incidente dio lugar a un oficio dirigido al alcalde mayor, para que este castigara a los responsables del ultraje. ${ }^{24}$ No obstante, al comprobar, días después, que nada sucedía, pues el alcalde mayor ni siquiera se había dignado responder, los guardas decidieron "corregir a los indios", intentando nuevamente realizar la ronda por el pueblo; pero cuando se disponían a realizarla, uno de los vecinos descubrió que la ronda estaba reconociendo una "casilla" donde se hallaron tres o cuatro onzas de tabaco y aunque no era el dueño del tabaco encontrado, comenzó a dar voces, convocando a un tumulto contra los empleados del monopolio. Mientras tanto y antes de que se armara el motín, el indio alborotador fue atrapado para llevarlo a la cárcel; sin embargo, sus gritos alertaron al resto de los vecinos, que vinieron en su ayuda y los dependientes de la Renta no tuvieron más remedio que soltarlo y abandonar rápidamente el sitio. ${ }^{25}$

Los guardas elevaron una queja a la administración de Puebla, que la trasladó a la Dirección General del Tabaco, donde se acusaba al alcalde mayor de Papantla, Manuel Cornejo, por las tibias disposiciones con las que respondió al resguardo a su petición de auxilio, sobre todo porque la jurisdicción de Papantla sobresalía por la proliferación de siembras clandestinas, cuyos habitantes se mostraban escandalosamente insolentes. Manuel Cornejo, teniente del regimiento de dragones, que desempeñaba el puesto de alcalde mayor desde $1777,{ }^{26}$ rechazó los cargos, acusando a los empleados de incompetencia en sus funciones. Las autoridades superiores amonestaron al alcalde mayor al que advirtieron que sería suspendido del empleo si se repetían hechos similares. ${ }^{27}$ La respuesta dada por la dirección general de la Real Renta da testimonio de la pugna entre los empleados del monopolio y el alcalde mayor de Papantla. Aunque para ser exactos, deberíamos mencionar el persistente antagonismo que se observará entre

\footnotetext{
${ }^{24}$ AGN, Tabaco, vol. 263.

25 Ibid. 103

${ }^{26}$ AGN, Alcaldes mayores, vol. 12, fs. 276-293v, y Reales Cédulas Originales, vol. 111, exp. ${ }^{27}$ AGN, Tabaco, vol. 263.
} 
los justicias locales y los empleados de la Renta. ${ }^{28}$ La información que nos ofrece el teniente visitador de Zacapoaxtla y otros hechos posteriores nos indica que la población mantuvo todos esos años un fuerte encono contra los guardas de la Renta del Tabaco, aversión que visiblemente era compartida por el alcalde mayor, cuya "criminal negligencia" lo convertía en cómplice de los indios contraventores que cada vez se mostraban más insolentes y cuya temeridad se manifestaba en la facilidad con la que se rebelaban contra el resguardo.

En 1787 la protección del capitán Manuel Cornejo terminó al ser separado de su puesto acusado de fraude en los bienes de comunidad. Fue sustituido interinamente por uno de sus tenientes, José María Morcillo, subteniente del regimiento de Zamora, quien había llegado a Papantla en 1784 nombrado por el fisco para asistir a la nueva cuenta de tributarios de la jurisdicción. ${ }^{29} \mathrm{El}$ ascenso de Morcillo debió romper los equilibrios existentes y el 23 de agosto de 1787 estalló un nuevo motín, pero ahora sí contra la Renta del Tabaco y vecinos españoles. Los amotinados clamaban contra los empleados de la Real Renta, quienes, junto con el alcalde mayor, corrieron a refugiarse a la iglesia, que fue también atacada repetidamente durante todo el mes que tardó en llegar el auxilio de las milicias de Teziutlán. Sin embargo, esas fuerzas no fueron suficientes para calmar las cosas, pues pronto la milicia fue sitiada por los rebeldes, y las autoridades se vieron obligadas a acudir al intendente de Veracruz, quien envió fuerzas regulares a Papantla, las que finalmente lograron imponer el orden. ${ }^{30}$ Desde el primer momento se culpó de complicidad a don Manuel Cornejo por encubrir a algunos de los amotinados, alimentando la insolencia de los indios de Papantla que no habían cesado de sembrar tabaco desde el establecimiento de la Renta. ${ }^{31}$ Las averiguaciones mostraron que Morcillo había promovido la quema de los sembradíos de tabaco para sembrar vainilla y para ello había manipulado las elecciones de la república de indios, a fin de que salieran electos elementos afines al alcalde y así controlar el comercio. Sin embargo, estos hechos sólo habían agravado conflictos preexistentes. La tensión había comenzado a principios de 1787 cuando varios comerciantes locales, entre ellos Juan Vidal, denunciaron como desocupadas las tierras de varios pueblos sujetos a Papantla, indudablemente atraídos por las nuevas oportunidades que ofrecía la produc-

${ }^{28}$ Ibid. En la respuesta de la dirección general se escribió: "No hay para don Manuel Cornejo, visitador, cabo, ni guarda que no sea delincuente, porque a todos los mira con aversión, la que juzgamos que hace un argumento nada equívoco de la buena conducta de ellos.”

${ }^{29}$ AGN, Alcaldes mayores, vol. 12, fs. 276-293v, General de parte, vol. 67, exp. 206, fs. 81-82v, e Indiferente virreinal, caja 2955, exp. 16, caja 1355, exp. 15, y caja 5270, exp. 17.

${ }^{30}$ AGN, Criminal, vol. 315, exp. 3, fs. 62-78. Véase Escobar, "Dirigencias", 2002, p. 222.

${ }^{31}$ AGN, Criminal, vol. 315, exp. 2, fs. 35v-36. 
ción de vainilla. Algunas tierras en cuestión le fueron otorgadas en venta a Vidal, contra lo cual protestaron las autoridades indígenas, que no fueron escuchadas y no encontrando otra salida se amotinaron. Sólo entonces la Audiencia revisó su decisión y dio razón a los indios, cancelando la venta y reconociendo que las tierras en efecto pertenecían a pueblos sujetos de Papantla. ${ }^{32}$ Vidal, además de ser uno de los más poderosos y prominentes comerciantes de la región, con fuertes intereses en el negocio de la vainilla, tenía a su cargo el fielato de Papantla. ${ }^{33}$ El resguardo del tabaco, bajo la autoridad del fiel, tenía a su cargo inspeccionar los sitios susceptibles de producción ilegal. Curiosamente, el mapa de producción clandestina de tabaco coincide perfectamente con el de la vainilla: Papantla, Cabezas, Espinal, Coxquihui, Cazones y Tenampulco. ${ }^{34}$ La vainilla estaba lista para ser cortada a mediados de marzo, pero podía cortarse antes de esa fecha, aún verde y así su precio era menor, pero con la ventaja de poder utilizar un sistema de secado más perfeccionado y sobre todo evitar el riesgo de pérdidas debido a los robos frecuentes que se cometían en los acahuales. ${ }^{35}$ Las visitas del resguardo comenzaban generalmente el 15 de febrero y partían de diferentes sitios (Papantla, Teziutlán y Zacapoaxtla) y no es difícil imaginar que durante esas visitas no sólo se destruía el tabaco ilegal, sino también se recolectaba la vainilla, por lo que es fácil percatarse del interés que tenía para los comerciantes locales controlar el resguardo del tabaco, que podía servir de argumento para obligar a los indios a entregar su vainilla a bajos precios.

La rebelión de 1787 no sólo tuvo como origen una cuestión de tierras, sino que en ella cristalizaron una acumulación de agravios, entre los cuales se hallaba la cuestión del tabaco, asunto que visiblemente estaba muy lejos de estar resuelto. Todo lo anterior nos permite observar que la siembra de tabaco, práctica ilegal desde hacía más de 20 años, no había sido eliminada y que los agentes de la Real Renta del Tabaco podían convertirse fácilmente en el blanco de las protestas y del resentimiento de los habitantes. La rebelión puso en evidencia la importancia que los indios otorgaban a la siembra de tabaco, pues además de representar una fuente de recursos, era también uno de los pilares en los que se asentaba la producción de los más importantes cultivos locales: maíz, vainilla y tabaco conformaban la trilogía del ciclo agrícola regional y del sistema de cultivo de tumba, roza y quema. En la llanura costera de Papantla se realizaban dos cosechas de maíz al año o se alternaban en la misma parcela una de maíz y una de

\footnotetext{
${ }^{32}$ Ibid.; Kourí, Pueblo, 2004, p. 68, 70, y AGN, Tierras, vol. 1225, exp. 17.

${ }^{33}$ AGN, Tabaco, vol. 123, exp. 3, Criminal, vol. 714, fs. 126-129, y vol. 315, fs. 30-31.

${ }^{34}$ Velázquez, Cuando, 1995, pp. 75-77, 101, y AGN, Criminal, vol. 714, y Tabaco, vols. 206 y 450 .

${ }^{35}$ Kourí, Pueblo, 2004, p. 86.
} 
tabaco. Al cabo de tres años la parcela se dejaba en barbecho, es decir, en acahual, a fin de restituir la fertilidad a la tierra, sembrándose allí vainilla. La vainilla estaba madura a mediados de marzo, pero en su defecto, también podía cosecharse verde, lo que disminuía su precio. A pesar de que en Papantla el proceso de secado de la vainilla era muy deficiente, su producto era muy aromático, por lo que tenía fuerte demanda en el mercado de exportación, en el que se vendía a precios altísimos, que incluso llegaban a superar el precio de la plata, proporcionalmente a su peso. Por un lado, los comerciantes hicieron todo para estimular el cultivo de acahual, prestando dinero a los indios, a cambio del cual esperaban un pago en vainilla. ${ }^{36}$ Sin embargo, los indios se resistieron a cambiar el equilibrio agrícola existente y en consecuencia no estuvieron dispuestos a abandonar el cultivo del maíz y del tabaco, con las consabidas consecuencias.

Después de 1787 no vuelve a registrarse un tumulto semejante, pero tampoco desaparecen las siembras clandestinas. Sin embargo, el conflicto entre los indios de Papantla y el resguardo, a causa del cultivo ilegal, va a desplazarse al subdelegado, quien encarnó la oposición a los empleados del resguardo, a través de la desobediencia pasiva a las órdenes que lo vinculaban a procedimientos represivos del monopolio. Los subdelegados fueron requeridos de manera creciente para cubrir funciones de verificación, control y represión en la lucha contra las siembras clandestinas que efectuaban los empleados del monopolio, lo que tropezó con la indolencia de los jueces que no obtenían de ello ninguna recompensa y por el contrario, ponían en riesgo los negocios que realizaban con los indios, lo que revela hacia dónde se inclinaba la balanza de intereses del subdelegado y los términos del "acuerdo" con los indios, que implicaba una tolerancia cómplice a las siembras de tabaco y una oposición sistemática del justicia a la política represiva realizada por el resguardo.

\section{SUBDELEGADOS Y SIEMBRAS CLANDESTINAS: CONSOLIDACIÓN DE UNA ALIANZA}

En 1791 el resultado de la visita realizada en Papantla presentó escasos resultados. El bajo volumen de tabaco incautado en este año, 118847 matas, fue muy inferior a lo que se produjo en las jurisdicciones vecinas de Huauchinango y Huayacocotla ese mismo año, representando menos de una tercera parte de lo incautado en estas. El escaso número de matas decomisadas en 1791 podría hacernos pensar que las siembras clandestinas

${ }^{36}$ Villaseñor, Theatro, 1746, p. 318; Kourí, Pueblo, 2004, pp. 70, 81-84; Velázquez, Cuando, 1995, pp. 65, 75, y Humboldt, Ensayo, 1822, t. II, p. 391. 
estaban en pleno declive, pero en 1793 el teniente visitador de la Real Renta Francisco de Zamitis aseguraba lo contrario. ${ }^{37}$ Señaló que en los últimos años se había registrado, anualmente, un incremento de las siembras, cuyo monto era difícil de calcular, pues los indios de Papantla habían adoptado la medida de anticipar sus siembras, de tal modo que la hoja estaba lista desde el mes de marzo y podía iniciarse la cosecha varias semanas antes. Los dueños de esas siembras tomaban en consideración la enorme extensión que debían recorrer los empleados de la Renta para hallarlas, sembrando en lugares alejados y distantes unas de otras. A la gran diseminación de las siembras se añadía lo áspero e intrincado de los montes, todo lo cual dificultaba enormemente la localización de los tabacales, situados en lo más "breñoso de los montes". ${ }^{38}$

No tenemos información detallada de las visitas que se llevaron a cabo entre 1791 y 1798 en Papantla, sin embargo sabemos que la ronda que iba a realizarse en 1799 debió ser interrumpida desde su inicio por conflictos surgidos entre el resguardo y el subdelegado, los que continuaron en 1800, alcanzando proporciones considerables.

En 1800 los empleados del resguardo decidieron cambiar de estrategia a fin de lograr resultados más efectivos en la lucha contra las siembras clandestinas. Los tres equipos de la ronda partieron al mismo tiempo de Papantla, tomando diferentes direcciones, a fin de intentar sorprender anticipadamente a los contraventores, en vez de salir de diferentes rumbos, como era costumbre. ${ }^{39} \mathrm{Y}$ los resultados alcanzados fueron excelentes, destruyéndose 273963 matas, ${ }^{40}$ lo que significa que las siembras clandestinas se habían incrementado notablemente. Comparando el volumen incautado en 1791 con el de 1800, el resultado lo supera en más del doble. La visita de 1800 no sólo sobresale por la creciente cantidad de tabaco confiscado, sino también por el abierto conflicto que se desatará entre el subdelegado de Papantla, don Esteban Tizón, y los guardas del estanco. La pugna ocurrirá principalmente por dos razones. La primera, por el incumplimiento del subdelegado al decreto del 1 de mayo de 1797 que le ordenaba perseguir a los culpables que no pudieran ser atrapados por los guardas de la Renta. Al parecer los subdelegados o sus tenientes no hicieron nada para cumplir esa orden y la siembra clandestina siguió sin ser reprimida con el vigor necesario, lo que le ofrecía una forma de protección. Inclusive algunos testimonios de los guardas señalaron que la escasa aplicación de los castigos causaba incremento en las siembras, como en

\footnotetext{
${ }^{37}$ AGN, Tabaco, vol. 114 .

${ }^{38}$ Ibid.

${ }^{39}$ AGN, Tabaco, vol. 183.

${ }^{40}$ Ibid., vols. 183 y 361.
} 
1791, cuando sólo 30\% de los infractores fue castigado. ${ }^{41}$ La segunda razón fue más explosiva pues tocaba directamente los intereses del resguardo. La cédula real del 4 de junio de 1799 obligaba a los guardas a obtener la certificación del subdelegado o de quien él designara para autentificar el número de matas destruidas durante la visita, de cuya constancia dependía la gratificación otorgada a los guardas. Sin ese documento no se autorizaría el pago de la recompensa a los dependientes de la Renta, que era un estímulo para perseguir las siembras ilegales a pesar de todas las incomodidades e inconvenientes que entrañaban las visitas. La falta de certificación podía retrasar por meses y hasta por años la finalización de la causa y ello demoraba igualmente el pago de las recompensas. El 18 de enero de 1800 el director general de la Real Renta, Silvestre Díaz de la Vega, expuso los problemas que derivarían de esta medida, anunciando los tropiezos que el resguardo enfrentaría para lograr la colaboración de los justicias, pues los subdelegados jamás aceptarían acompañar a los resguardos como subalternos, lo que considerarían indecoroso; además, se tendrían que tomar en consideración los casos (como el de Papantla), donde la gran proliferación de siembras provocaba la existencia de varias visitas que actuaban simultáneamente, lo que impedía al justicia asistir a todas. ${ }^{42}$ En resumen, el director general de la Real Renta advertía del fracaso al que estaba condenada la cédula del 4 de junio de 1799, que sólo provocaría "un seminario de discordias en que tropezase el feliz suceso de la extinción de tabacos clandestinos". ${ }^{43}$

La orden revela la desconfianza de las autoridades, que sospechaban el abultamiento de los volúmenes incautados a fin de percibir mayores recompensas. Sin embargo, como ya lo había vaticinado Díaz de la Vega, el remedio propuesto causaría mayores dificultades, no sólo para los guardas del monopolio, sino también para las autoridades judiciales y administrativas locales. Si en 1799 ya se había registrado un serio conflicto entre los empleados de la Renta y el subdelegado de Papantla, en el año de 1800 la pugna tomó mayores proporciones por la aplicación de la orden del 4 de junio, pues si la falta de cumplimiento de la orden de 1797 no tenía consecuencias directas para los guardas, no era el caso con la de 1799.

Tres semanas después de haberse iniciado las visitas de la jurisdicción de Papantla, a mediados de febrero de 1800, los guardas y cabos del resguardo recibieron el oficio donde se les ordenaba presentar un certificado del justicia con el número de matas exterminadas, el que transfirieron al subdelegado Esteban Tizón. Tanto el subdelegado como el teniente de

\footnotetext{
${ }^{41}$ AGN, Criminal, vol. 714.

${ }^{42}$ AGN, Tabaco, vol. 197.

${ }^{43}$ Ibid., vols. 183 y 197.
} 
justicia rechazaron la solicitud de los empleados de la Renta, negándose terminantemente a acompañar al resguardo en sus visitas, aunque accedieron a tomar los testimonios de los reos que ya estaban en la cárcel de la cabecera, sugiriendo que los tabacos confiscados se trasladaran a la cabecera para proceder a su destrucción frente a la autoridad, "como antes se acostumbraba". Al finalizar las visitas, los autos fueron enviados sin la debida atestación y el fiscal de Hacienda rechazó las causas debido a la falta de certificación de acuerdo con la orden de 1799. Los autos fueron trasladados al gobernador de Veracruz, quien debía devolverlos al subdelegado, quien a su vez debía certificarlos o explicar la razón por la cual había omitido la indispensable constancia. ${ }^{44}$

Esteban Tizón justificó la falta de certificación por no poder estar presente en las visitas, al mismo tiempo que expresaba su desconfianza por las atestaciones presentadas por los guardias, firmadas por desconocidos, sabiendo que muy pocos sabían escribir en su jurisdicción. Por un lado, señaló que la impunidad de la que gozaban los contraventores ocurría por la negligencia de los propios resguardos, pues en su mayoría eran "guardas patricios" y los que no, estaban casados con indias, por lo que todos estaban emparentados con la mayoría de los infractores, disimulando su indulgencia con la inclusión de los nombres en la lista que debían pasar al justicia, quien no conocía a los reos ni sabía dónde vivían, por lo que quedaban sin castigo. Por otro lado, advirtió que el peso de las obligaciones de su empleo le impedía asumir la persecución de los reos. Tizón opinó que el resguardo debía emplear más tiempo en perseguir a los responsables para obligarlos a cumplir con el castigo, pues durante nueve meses del año en que los dependientes de la Real Renta no efectuaban rondas, tampoco visitaban los estanquillos, ni velaban por mantener el fielato bien abastecido de tabaco, con grave detrimento para la Renta y los consumidores más pobres. ${ }^{45}$ En filigrana, el subdelegado acusaba a los empleados del fielato de proteger al contrabando con su negligencia, pues el desabasto también ocasionaba siembras ilegales. Asimismo, señaló irregularidades en las visitas insinuando que los resguardos abultaban el número de matas encontradas, disimulándolo con certificaciones de personas que no tenían la acreditación necesaria para llevar a cabo esas diligencias, pues con frecuencia esas personas no sabían ni escribir, sugiriendo que algunas certificaciones presentadas podían ser falsas. El subdelegado con su respuesta no hacía más que alimentar las sospechas que había originado la real cédula

${ }^{44}$ AGN, Tabaco, vol. 183.

${ }^{45} \mathrm{Ibid}$. El subdelegado incluso señaló que el fiel de Papantla, José Rodríguez, cuando se anunciaba escasez de tabacos, ofrecía a los ricos hacer sus provisiones e inclusive había llegado a hacer remisiones de tabaco a lugares distantes al fielato, con perjuicio de los pobres. 
del 4 de junio de 1799 y agregaba nuevos delitos como suplantación y falsificación de documentos.

Los problemas entre los guardas y el subdelegado de Papantla no eran nuevos, remontaban a años atrás y derivaban también de rivalidades personales. ${ }^{46}$ Los guardas y el fiel, en respuesta a las insidiosas observaciones hechas en su contra por el magistrado, fundaron su defensa reuniendo todos los casos litigiosos que habían enfrentado al subdelegado y la Renta del Tabaco desde 1791, a fin de presentar todas las irregularidades cometidas por el magistrado y en particular demostrar la especial animosidad que desde entonces tenía contra los empleados del monopolio, cuyas actividades se había empeñado en obstaculizar sistemáticamente. Sin embargo, de todas las faltas que se le atribuían al subdelegado, la más seria fue la responsabilidad que le imputaba al magistrado en la liberación de algunos de los indios culpables de siembras clandestinas. Según esto, a muchos de los contraventores, cuando eran capturados por el resguardo, el subdelegado los dejaba libres a cambio del pago de una multa. ${ }^{47} \mathrm{La}$ gravedad del delito atribuido al subdelegado aumentaba en la medida en que la fuga de contraventores había marcado de manera importante la década de 1790. Recordemos que en las visitas de 1791 sólo se había logrado arrestar a $30 \%$ de los contraventores. Aunque en 1800 la ronda pareció mucho más eficaz, lográndose detener y castigar a $65 \%$ de los contraventores, la falta de certificación del subdelegado dejó flotando en el aire la veracidad de tan alta cifra.

No obstante las pruebas evidentes de la existencia de rencillas personales que alimentaban, en gran parte, el conflicto entre ambas autoridades, es indudable que la decisión de involucrar a los subdelegados en la detención de los reos por siembras clandestinas también planteaba problemas de jurisdicción, jerarquía y clientela, lo que en el antiguo régimen era de gran importancia. Este problema se revela claramente en la respuesta que dio el magistrado a las demandas de persecución y aprehensión que le hicieron los resguardos en una ocasión en que descubrieron la presencia de infractores en el pueblo, replicando: "no ser su criado y que fueran ellos a buscarlos y traerlos presos, si querían, que para eso les pagaban", por lo que los empleados de la Renta se quejaron por verse obligados a encargarse de la detención de los responsables a fin de evitar que se quedaran

${ }^{46}$ Ibid.

${ }^{47} \mathrm{Ibid}$. Cuando los resguardos quisieron presentar al indio al que supuestamente el subdelegado había dejado libre a cambio del pago de una multa, resultó que había muerto el año anterior y los guardas no pudieron presentar a ningún otro testigo que se hubiese beneficiado de esa gracia. 
sin castigo. ${ }^{48}$ Esta ambigüedad, y los problemas que de ella se derivarían, ya había sido señalada por el director general de la Real Renta a principios de $1800 .{ }^{49}$ No obstante, las acusaciones hechas por el subdelegado contra el resguardo tampoco eran todas producto de su fantasía malévola, como querían hacer creer los empleados de la Renta, pero no entraremos en esos detalles. Sólo queremos destacar que la denuncia hecha contra el subdelegado de Papantla en 1800 coincide con la que presentó en 1805 el guarda encargado de las visitas en las jurisdicciones vecinas de Tulancingo, Huauchinango y Huayacocotla, quien señaló que entre los subdelegados de los partidos donde efectuaba sus rondas había una actitud de condescendencia generalizada, advirtiendo que con su negligencia se oponían a la captura de los responsables de siembras clandestinas. ${ }^{50}$

Los guardas habían acusado al subdelegado de Papantla no sólo de negligencia, sino de abierta protección a los contraventores y en este sentido nos interesa destacar el caso del indio José Galicia, liberado por intervención del subdelegado, lo que provocó el conflicto entre este y el resguardo en 1799. José Galicia había sido acusado en 1799 de reincidente, junto con otros seis o siete contraventores, quienes habían huido, por lo que fueron incluidos en la lista entregada al subdelegado, quien debía capturarlos. Diez días después el subdelegado no había detenido a nadie y el cabo del resguardo, Juan José Balderrama, acudió al capitán de milicias del lugar, Juan Villamil, para que le franqueara la cárcel del cuartel a fin de encerrar ahí a los contraventores que lograra atrapar y así evitar que el subdelegado los liberara. Fue entonces cuando logró capturar al indio José Galicia, que fue apresado cuando se disponía a conducir a Huauchinango dos cargas de cera, propiedad del subdelegado Tizón, del que resultó ser arriero. El subdelegado, al saber de la prisión de su arriero, mandó llamar al cabo de la Renta, ordenándole poner en libertad a Galicia, pero el guarda se opuso, hasta que el reo no cumpliera su castigo. El subdelegado procedió a poner en libertad a su arriero y en la cárcel al cabo, quien desde la prisión elevó

\footnotetext{
${ }^{48} \mathrm{Ibid}$. Había un malentendido en la real orden de 1797 pues ella no eximía el resguardo de la responsabilidad de capturar a los reos. El subdelegado debía intervenir en el caso donde los resguardos no pudieran encontrar a los contraventores, pero es evidente que en la presente declaración, los infractores en cuestión estaban al alcance de los empleados de la Renta y en ese caso también era su responsabilidad capturarlos. La orden expedida a subdelegados y miembros del resguardo dice claramente "sin que por el cuidado que los subdelegados, sus tenientes y encargados de la administración de justicia deben poner en la persecución de los contraventores [...] se liberten a los visitadores y demás de la obligación de ejecutar lo mismo con los reos que ellos puedan aprehender", en AGN, Tabaco, vol. 197. No obstante, vemos que la yuxtaposición de jurisdicciones y su fragmentación provocó una dinámica de enfrentamientos crónicos en el interior del gobierno virreinal, y las rivalidades entre el subdelegado de Papantla y los empleados de la Real Renta del Tabaco son un ejemplo de ello.

${ }^{49}$ AGN, Tabaco, vols. 183 y 197.

${ }^{50}$ Ibid., vol. 325.
} 
su queja al factor de Puebla. La ronda que había iniciado Balderrama con sus dependientes fue suspendida, pues los resguardos no se atrevieron a continuarla por el temor que les causaban los rumores que corrían entre los indios, que interpretaron la prisión de Balderrama como una prueba que desautorizaba la persecución contra sus siembras de tabaco. La prisión del cabo, según testimonio de un guarda de la Real Renta, había regocijado tanto a los indios e indias de Papantla, que entre ellos habían estado comentando que esperaban que el castigo impuesto al cabo de la Renta sirviera de escarmiento a esos "comisarios hambrientos". ${ }^{51}$

Un elemento que sobresale en el conflicto registrado entre los empleados de la Real Renta del Tabaco, además de la resuelta protección con la que favoreció el subdelegado Tizón a los contraventores de su jurisdicción, es la información que se desprende sobre la actividad comercial del subdelegado, quien en 1800 aparece como propietario de una tienda en $\mathrm{Pa}$ pantla. Esteban Tizón era un peninsular originario de Cádiz, quien desde principios de la década de 1770 se encontraba ya establecido en la ciudad de Veracruz ejerciendo una actividad comercial. ${ }^{52} \mathrm{~A}$ finales de la década de 1770, Tizón ya había logrado una posición acomodada; era propietario de la fragata Santo Cristo de la Veracruz, con la que realizaba un intenso comercio por toda la región del Golfo, llegando incluso hasta Campeche. Al cabo del tiempo Tizón alcanzó una posición encumbrada, pues en 1787 era comandante de milicias urbanas de Veracruz. ${ }^{53}$ Por su actividad durante esos años, Tizón debió advertir lo rentable que era el comercio con la región del Totonacapan y visiblemente buscó consolidar su posición en esa zona, y en 1788 consiguió ser nombrado subdelegado de Papantla. ${ }^{54} \mathrm{Al}$ finalizar su periodo de funciones en la subdelegación, en 1797, logró obtener la renovación del empleo con base en las buenas referencias que se recogieron en el marco de la investigación que hizo el virrey sobre su comportamiento, destacando el buen desempeño que había tenido al frente de Papantla durante ese tiempo. ${ }^{55}$ Paralelamente su posición se vio reforzada en esos años al obtener en 1794 el grado militar de teniente coronel de milicias urbanas. ${ }^{56} \mathrm{Y}$ visiblemente durante todo ese tiempo no abandonó la actividad comercial que había iniciado en Veracruz varios lustros antes

${ }^{51}$ AGN, Tabaco, vol. 183.

${ }^{52}$ AGN, Indiferente virreinal, caja 3819, exp. 12.

${ }_{53}$ AGN, Marina, vol. 41, exp. 7, Archivo Histórico de Hacienda, vol. 345, exps. 77, 78 y 148 , Criminal, vol. 315, exp. 2.

${ }^{54}$ AGN, Tabaco, vol. 123, exp. 3.

${ }_{55}$ AGN, Correspondencia de virreyes, vol. 188, fs. 46-47, y Reales Cédulas Originales, vol. 184, exp. 1.

${ }^{56}$ AGN, Correspondencia de virreyes, vol. 178. El grado de teniente coronel de las milicias otorgaba los privilegios del fuero militar que consistía en un gran número de exenciones y beneficios, que eran especialmente apreciados por los comerciantes. Marchena, Oficiales, 1983, p. 80. 
de llegar a Papantla, extendiéndola a los pueblos de la región, fuera de su jurisdicción, como lo acreditan las cargas de cera que debía llevar Galicia a Huauchinango. Esa actividad comercial necesariamente lo vinculaba a los intereses de los indios, quienes eran los principales abastecedores de los productos que vendía el subdelegado: cera, vainilla, piloncillo, chile, maíz, entre otros. Esa relación debió incluir el reparto de mercancías o crédito, que el subdelegado sin duda continuó realizando y donde la siembra ilegal de tabaco, que gozó de una protección de facto de parte de este, como se pone de manifiesto en el caso del indio José Galicia o por omisión a través del descuido en la persecución de los contraventores, siguió siendo un elemento importante en el acuerdo entre el magistrado y los indios. A la luz de la persistente siembra ilegal, que no decreció en esos años, sospechamos, que el acuerdo incluía la aceptación de las mercancías de repartimiento, incluso durante el periodo de prohibición, a cambio de la tolerancia y la eventual protección del subdelegado a la siembra ilegal. La mayor parte del tiempo Tizón cerró los ojos al cultivo clandestino que realizaban los indios de su jurisdicción. Incluso podemos avanzar que el cultivo ilegal sirvió para financiar las actividades comerciales del magistrado, en la medida en que el producto de su venta ayudaba a pagar las mercancías o el dinero a crédito que entregaba el subdelegado a los indios. Esta suposición se verá apoyada por los comentarios del fiel de Zacatlán, que desde 1786 señaló el vínculo existente en Papantla entre el repartimiento y la siembra clandestina de tabaco. En el marco del conflicto que opuso a los dependientes del resguardo de Papantla y al alcalde mayor, el administrador del tabaco de Zacatlán, Gaspar de Gómara, señaló que los alcaldes mayores no cuidaban otra cosa que no fuera el que los indios pudieran conseguir con qué pagar los repartimientos, aun haciendo siembras clandestinas de tabaco.$^{57}$ Y como vemos, la actividad comercial de los alcaldes mayores no terminó con el establecimiento de las intendencias, solamente adquirió otra faceta, que sin duda requirió la complicidad de los pueblos que debieron aceptarlo a cambio de algo, y ese "algo" en Papantla fue la tolerancia a la siembra clandestina de tabaco. Es interesante destacar que, contrariamente a lo que afirma Pietschmann, en la región de la sierra de Puebla y las llanuras de Papantla sí existió "esa especie de pequeño repartimiento a través de tiendas mantenidas por los funcionarios reales", como lo acredita el caso de Tizón, pero también como quedará de manifiesto en Zacatlán, en 1811, donde Sebastián Piedras, hijo del subdelegado, era propietario de uno de los dos establecimientos comerciales más importantes de ese pueblo. ${ }^{58}$

\footnotetext{
${ }^{57}$ AGN, Tabaco, vol. 263.

${ }^{58}$ Pietschmann, Mexiko, 2000, p. 117, y AGN, Historia, vol. 103, exp. 14, fs. 60-61.
} 
En el conflicto que nos ocupa, los empleados de la Renta intentaron por todos los medios hundir al subdelegado, involucrándolo en otros actos ilícitos en relación con la Renta del Tabaco; sin embargo, para ser honestos, no se hizo ninguna referencia a prácticas relativas al repartimiento de mercancías. En 1800 el fiel de Papantla acusó al subdelegado de complicidad en la reventa de puros y cigarros fuera de los lugares autorizados. Según la denuncia, la venta de labrados procedentes de la fábrica de Orizaba había tenido lugar en el domicilio y en la tienda del subdelegado de Papantla al doble del precio establecido (recordemos que el fielato de Papantla estaba bajo la jurisdicción de la factoría de Puebla). Aunque el supuesto tráfico había sido realizado por el escribiente y el encargado de la tienda del subdelegado, el fiel señaló que no podía haber sido ignorado por el magistrado. ${ }^{59}$ Como sabemos, la venta legal sólo podía hacerse en los estanquillos de la administración, en ningún otro lugar, así se tratara de tabaco procedente de las fábricas reales. Cada punto de venta legal estaba bajo la jurisdicción de una administración y una fábrica, de donde debían proceder los labrados. Si bien la venta del tabaco sólo podía realizarse en los estanquillos autorizados, esos tampoco tenían licencia para vender tabaco de una administración distinta a la suya.

La acusación intentaba involucrar al subdelegado en prácticas muy extendidas que habían dado lugar, ese mismo año, a un bando de prohibición, donde los revendedores eran considerados como contrabandistas. En febrero de 1800 se publicó un bando en el que se reiteraba la prohibición de venta de tabaco de las fábricas reales fuera de las administraciones, tercenas, fielatos y estanquillos correspondientes. Las penas a las que se hacían acreedores los responsables de esa práctica ilegal eran semejantes a las condenas señaladas a los contrabandistas; la severidad del castigo aplicado a esa transgresión indica lo extendido de la práctica. ${ }^{60}$ Lo cierto es que el desabasto debió ser grave pues estimulaba tanto la reventa como la producción ilegal. En 1803 el director general de la Real Renta del Tabaco, Silvestre Díaz de la Vega, señalaba al partido de Papantla como una de las jurisdicciones con mayor incidencia de siembras clandestinas de tabaco, a pesar del empeño del resguardo en destruir los cultivos y perseguir anualmente a los contraventores, que hasta entonces habían estado protegidos por el subdelegado, quien no los arrestaba, dejando impunes sus delitos, pues cuando los transgresores eran capturados por los guardas,

${ }^{59}$ AGN, Tabaco, vol. 183.

${ }^{60}$ AGN, Tabaco, vol. 197. Las pruebas de la reventa presentadas al comisionado eran tan endebles que parecen fabricadas por el resguardo, a fin de acusar al subdelegado del delito que estaba entonces en boga. 
el subdelegado los liberaba a cambio del pago de una multa. ${ }^{61}$ Finalmente, después de tres años de impugnaciones y réplicas, en 1803 fue destituido Esteban Tizón, siendo reemplazado por don Manuel Puebla y Taboada. ${ }^{62}$ Sin embargo, con la llegada del nuevo magistrado las fricciones a causa de las reales órdenes de 1797 y 1799 no cesaron.

En 1805 el subdelegado de Papantla, Manuel Puebla y Taboada, calificó nuevamente de irrealizable la orden de 1799 que establecía que el subdelegado certificara el número de matas confiscadas y de leguas recorridas por los resguardos durante la visita, manifestando que si el subdelegado otorgase una certificación semejante, "se haría desde luego acreedor, a que no se pudiese dar crédito a sus documentos: y a consecuencia no digo difícil, sino moralmente imposible, que el subdelegado acompañe a los resguardos, como se está pretendiendo, por la inconcusa razón de que siendo tres los resguardos de esta jurisdicción y cada uno por muy distante rumbo, fuera preciso que el subdelegado se trilocase". ${ }^{63}$

En ese mismo sentido respondió el subdelegado al resguardo, rechazando categóricamente sus continuas solicitudes para cumplir con la orden del 4 de junio de 1799 .

Si a vista de cuanto tengo expuesto volviesen en los años siguientes los resguardos con tales pretensiones, vendré en conocimiento de que no procuran otra cosa que molestarme, y quitarme el tiempo que necesito para mejor desempeño de mi obligación en el empleo, que obtengo, que no es de tan poca estima para sujetarme a andar entre los montes a pie como los guardas, ni menos poner quien los acompañe, porque no tengo, ni vuestras mercedes me suministran para pagarlo. ${ }^{64}$

En 1806 el director de la Real Renta, Díaz de la Vega, volvió a plantear las dificultades para el cumplimiento de la real orden de 1799, poniendo en evidencia la necesidad de mantener un mínimo de armonía entre el marco normativo y su aplicación en el ejercicio de la práctica cotidiana, cuyos problemas él mismo había anticipado desde enero de $1800 .^{65}$ Seis años después el director veía cumplidas sus predicciones, advirtiendo que los conflictos entre subdelegado y empleados del resguardo no cesarían hasta que no se revocara la real orden, lo cual supuso también la victoria de la protección informal que otorgaron los magistrados a la siembra ilegal del tabaco.

\footnotetext{
${ }^{61}$ AGN, Tabaco, vol. 183. Otros decían haber oído decir que la multa que les hacía pagar el subdelegado era en especie.

${ }^{62}$ AGN, Tabaco, vol. 183, y Reales Cédulas originales, vol. 189, exp. 58, 1 f.

${ }^{63}$ AGN, Tabaco, vol. 206.

${ }^{64}$ Ibid.

${ }^{65} \mathrm{Ibid}$.
} 


\section{COnClusiones}

A partir del establecimiento del monopolio del tabaco se comenzaron a definir ciertas regiones como productoras clandestinas de tabaco por el alto índice de siembra ilegal, entre ellas destacó la jurisdicción de Papantla, donde se manifestó, desde los primeros meses, una oposición contra el estanco: en septiembre de 1765 el tabaco reunido por el alcalde mayor fue consumido por el fuego, e igual suerte corrieron las casas reales, el disgusto era patente. Sin embargo, dos años después, cuando todo el pueblo se rebeló contra el alcalde mayor, la oposición al estanco desapareció de las reclamaciones que hacían los habitantes de Papantla, contrariamente a lo que sucedía en otros lados de Nueva España, y lo más sorprendente fue el mutismo que guardaron por las prácticas abusivas del alcalde mayor por un reparto de mercancías excesivo, confiscatorio de la economía local y ello, a pesar de la reputación que tenían los papantlecos de levantiscos y difíciles. Se sabe que el reparto abusivo fue una de las causas más frecuentes de motines, por lo que el incomprensible silencio de los indios de Papantla en esas circunstancias nos hace suponer la aparición de un "nuevo acuerdo" entre los indios y el alcalde mayor, que incluía la tolerancia a las siembras de tabaco. Esta alianza permitiría al cultivo ilegal gozar de protección a través de la pasividad del justicia y, a cambio, los indios aceptaban un repartimiento, incluso excesivo, que puede calificarse de "voluntario a fuerza" por contener los dos términos de la formulación. Las prohibiciones derivadas del establecimiento del monopolio provocaron una relación mucho más desequilibrada entre alcaldes mayores e indios, sobre todo si estos se empeñaban en seguir sembrando tabaco, lo que implicaba aceptar voluntariamente los abusos del magistrado. Sin embargo, el nuevo acuerdo tampoco significó ceder a todas las exigencias de los alcaldes mayores, como se puso de manifiesto en el tumulto de 1767, cuando los indios se amotinaron para defender a uno de los suyos.

En efecto, el establecimiento del estanco originó una forma sofisticada de evasión que incluyó un acuerdo entre los indios y los alcaldes mayores y luego, los subdelegados, independientemente del repartimiento. Sin embargo, los indios usaron el repartimiento para conseguir el apoyo del alcalde mayor. Al prohibirse el repartimiento, se modificaron esos términos, lo que provocó el levantamiento de 1787, lo que puso en evidencia que no sería tan fácil alterar la alianza existente hasta entonces. Por lo demás, las rivalidades derivadas del control de la producción local, particularmente de vainilla, y la supresión del repartimiento, permitieron a los indios recuperar y reforzar el pacto con el subdelegado, sólo que en términos más equilibrados. Aunque la prohibición del repartimiento no eliminó el 
acuerdo entre indios y subdelegado, tuvo efectos disuasivos desalentando los abusos excesivos del magistrado.

Contrariamente a lo que se podía pensar, el repartimiento en Papantla no correspondía al modelo de zonas "subdesarrolladas", pues no se hallaba tan incomunicado como se supone, al contar con varias alternativas de aprovisionamiento o venta de productos, por tierra y por mar, beneficiándose además con la posibilidad de un cultivo altamente rentable y especializado (la vainilla) que le permitía acceder a fuentes de crédito diferentes del repartimiento, que además se disputaban ese mercado de producción. ${ }^{66}$ Sin embargo, las prohibiciones implantadas por el monopolio introdujeron elementos que beneficiaron a alcaldes mayores y subdelegados, aunque también los comerciantes intentaron utilizar el monopolio en su favor. Los mismos comerciantes interesados en favorecer la producción vainillera participaron directamente en las actividades del monopolio. Coordinar y favorecer eficientemente las estrategias de represión del tabaco ilegal podía contribuir al incremento de la producción de vainilla.

Se sospecha que los alcaldes mayores y luego los subdelegados cerraron los ojos a la producción clandestina de tabaco y a cambio los indios aceptaron el repartimiento, incluso cuando este estuvo formalmente prohibido, reembolsando al subdelegado en dinero o con productos locales, que incluían la cera y la vainilla. Es fácil imaginar que el magistrado obtenía mayores ganancias si el pago se hacía en especie, pues ello le permitía vender a precios altos sus manufacturas y comprar a menor valor los preciosos productos que se obtenían en la región: vainilla, cera, maíz, pimienta y piloncillo, entre otros. Para los alcaldes mayores y luego para los subdelegados fue ventajoso contar con la prohibición del cultivo del tabaco, pues eso mantuvo claramente a su favor los términos del contrato con los indios, hasta que el repartimiento fue proscrito y los indios pudieron restablecer "un acuerdo" más equitativo y el justicia asumió directamente la oposición a las medidas represivas del monopolio. Las pugnas entre las autoridades provinciales y los empleados del resguardo constituyeron una protección adicional para la siembra ilegal de tabaco, pues ese antagonismo fue una dificultad más para la represión de estas siembras. Los indios contraventores en vez de oponerse violentamente a la destrucción de sus tabacales, cuando eran sorprendidos, adoptaron la estrategia de huir, sabiendo que no serían castigados ulteriormente. La negligencia de las autoridades provinciales, a quienes fue confiada la obligación de socorrer al resguardo en la persecución de los infractores, mantuvo altas las tasas de impunidad, que llegaron a alcanzar hasta 70 por ciento. ${ }^{67}$

\footnotetext{
${ }^{66}$ Kourí, Pueblo, 2004, pp. 70, 132, y AGN, Criminal, vol. 714, fs. 126-129v.

${ }^{67}$ En 1791 los contraventores detenidos apenas llegaron a 30\%. AGN, Criminal, vol. 714.
} 
En cuanto a la aplicación de las medidas represivas contra las siembras clandestinas, operadas por el resguardo, aparentemente esas no causaron mayor oposición pues simplemente no se aplicaron, y después de 1766 el descontento provocado por el establecimiento del monopolio del tabaco parece disiparse. En realidad los indios continuaron sembrando con la complicidad de las autoridades, como se puso en evidencia en 1785, cuando 20 años después de haberse establecido el monopolio se presentaron brotes de violencia que se repitieron con particular intensidad en 1787, cuando se registró una sublevación que duró varias semanas y que tuvo como epicentro la cuestión de la prohibición de la siembra de tabaco, que desató una reacción iracunda entre los campesinos que se rebelaron contra el resguardo y el alcalde mayor a causa de la destrucción de sus tabacales. El equilibrio alcanzado hasta 1787 fue roto con la reactivación de las medidas contra la siembra clandestina del tabaco, emprendidas por el virrey Gálvez, que se vieron reforzadas por la prohibición del repartimiento ocurrida en 1786 y que dio espacio al avance de intereses económicos relacionados con la producción de vainilla, cuyo mercado se encontraba en plena expansión y estaba atrayendo capitales foráneos que competían con los intereses de los indios. A principios de 1787 don Juan Vidal, poderoso comerciante local, había perdido la ocasión de apoderarse de las tierras de algunos pueblos de Papantla que declaró como realengas, pero seguramente no tuvo dificultad para convencer al alcalde mayor interino de los beneficios que conseguirían si obligaban a los indios a dedicar una mayor extensión de sus tierras al cultivo de vainilla, persiguiendo eficazmente la siembra ilegal de tabaco; para ello el magistrado debía sepultar todo acuerdo que protegiera el repartimiento, que además se había vuelto ilegal, y las ganancias que prometía el comercio de la vainilla excedían ampliamente los beneficios que podía obtener el alcalde mayor por el reparto de mulas y otras mercancías. Sin embargo, la reacción violenta de los indios, desatada por la destrucción de sus tabacales, debió enfriar las agresivas estrategias empresariales de Vidal y Morcillo. El alcalde Morcillo representaba intereses comerciales específicos y fáciles de descifrar por la razón que lo llevó a Papantla en 1784: formar la nueva cuenta de tributarios, cuya matrícula servía también para calcular la carga de repartimiento que podían asumir los pueblos y, como destaca Danièle Dehouve, el repartimiento era un complemento del tributo, cuyo pago era garantizado por el aval del magistrado, normalmente un comerciante capitalino. ${ }^{68}$ Emilio Kourí señala la dificultad para explicar las razones que impidieron el desarrollo del cultivo comercial de la vainilla en Papantla a fines de la

${ }^{68}$ Dehouve, “Crédito”, 1998, pp. 161 y ss. 
época colonial. ${ }^{69}$ La respuesta debe estar en la oposición de los campesinos del Totonacapan y su concepción de la producción agrícola, que la entendían como una asociación complementaria de cultivos que, por un lado, aseguraba la subsistencia y, por otro, mitigaba los efectos negativos de los fenómenos meteorológicos, tan recurrentes en esa región, lo que garantizaba su autonomía y diversificaba los riesgos, por lo que rechazaron sistemáticamente el desarrollo del monocultivo al que los empujaban los intereses comerciales. Sin embargo, no debemos soslayar la importancia atribuida al tabaco entre las sociedades indígenas desde la época prehispánica; considerada como la planta sagrada más importante, dotada de un poder curativo excepcional, usada de muy diversas maneras. Nahuas y mayas honraban el tabaco como deidad, pues "ahuyentaba a la misma muerte" por ser "el gran señor de las dolencias", y su uso se mantuvo vigente durante toda la época colonial, ${ }^{70}$ lo que explica en gran parte la persistencia de su cultivo, a pesar de todos los problemas que acarreaba. El tabaco no sólo significó una fuente de recursos estimable, sino que también formaba parte integrante del cosmos. Por un lado estuvo la importancia que tenía en el ciclo agrícola local, que aseguraba la sobrevivencia y, por otro lado, al ser considerado receptáculo de la potencia divina, su cultivo debía ser conservado, no obstante todos los perjuicios que ocasionaba su siembra.

La política represiva contra la siembra ilegal de tabaco no logró eliminarla, pues lejos de provocar una disminución paulatina de la producción, esta no dejó de incrementarse, como lo señaló en 1793 el visitador Zamitis. Todo lo anterior también nos muestra que las medidas de control a través de las cuales se intentaba establecer mecanismos de vigilancia para evitar el fraude y la corrupción, en más de una ocasión sólo provocaron la exacerbación de las rivalidades existentes entre las autoridades. La yuxtaposición de jurisdicciones que las reformas habían intentado enmendar no lograron ser eliminadas de la nueva organización administrativa adoptada en $1786 \mathrm{y}$, en vez de erradicar conductas indebidas, como en este caso el abultamiento de los decomisos, las medidas tomadas para evitar esos problemas sólo contribuyeron a obstaculizar el buen funcionamiento de la administración virreinal, cuando no lo inmovilizaron.

La siembra clandestina de tabaco debe ser vista también como una forma de resistencia activa que fácilmente podía transformarse en una reacción violenta. El límite entre una y otra formas de oposición fue muy tenue, amenazando siempre con convertirse en una rebelión abierta, pero los alcaldes mayores y luego los subdelegados se convirtieron en una válvula de escape que evitó mayores sublevaciones. La protesta contra la pro-

\footnotetext{
${ }^{69}$ Kourí, Pueblo, 2004, p. 85.

${ }^{70}$ Garza, "Uso", 2001, pp. 100-101.
} 
hibición adoptó rasgos colectivos o formas de resistencia activa individual (la siembra), en cuyo caso el castigo pudo ser mitigado, e incluso evitado, a través de la fuga, a diferencia de la rebelión colectiva, que conllevaba irremediablemente a la represión generalizada, pues la rebelión siempre fue vista por las autoridades virreinales como una amenaza al orden colonial.

Sin importar lo severa que pudo ser la represión contra la siembra clandestina, ni las transformaciones que trajeron las reformas borbónicas, los indígenas del Totonacapan lograron servirse de los intersticios resultantes del repartimiento y los intereses comerciales, encontrando la manera de establecer las alianzas necesarias para seguir cultivando tabaco, cuya siembra formaba parte importante de su cosmovisión y su economía, pero también era una fuente de beneficios para muchos, incluyendo al rey y a las autoridades locales, pues de las ganancias que obtenían los indios de su ilegal tráfico se pagaban los tributos, las obvenciones religiosas y las mercancías de repartimiento.

\section{FUENTES CONSULTADAS}

\section{Archivos}

AGN Archivo General de la Nación, México.

\section{Bibliografia}

Castro Gutiérrez, Felipe, Nueva ley y nuevo rey. Reformas borbónicas y rebelión popular en Nueva España, México, El Colegio de Michoacán/Universidad Nacional Autónoma de México, 1996.

Deans-Smith, Susan, Bureaucrats, Planters, and Workers. The Making of the Tobacco Monopoly in Bourbon Mexico, Austin, University of Texas Press, 1992.

"El estanco del tabaco en el México borbónico" en Agustín GonZÁlez Enciso y Rafael Torres SÁnchez (eds.), Tabaco y economía en el siglo XVIII, Pamplona, Universidad de Navarra, 1999, pp. 79-106.

Dehouve, DaniÈLE, "El crédito de repartimiento por los alcaldes mayores, entre la teoría y la práctica” en MARÍA DEL PILAR LóPez CANO y GuILlermina del VALLE (coords.), El crédito en Nueva España, México, Instituto de Investigaciones Dr. José María Luis Mora/El Colegio de Michoacán/El Colegio de México/Instituto de Investigaciones Históricas-Universidad Nacional Autónoma de México, 1998, pp. 151-175. 
Am. Lat. Hist. Econ., año 19, núm. 3, septiembre-diciembre, 2012, pp. 206-234

Ducey, Michael T., "Village, Nation and Constitution: Insurgentes Poltics in Papantla, Veracruz, 1810-1821”, Hispanic American Historical Review, Duke University Press, núm. 79, vol. 3, 1999, pp. 463-493.

Escobar Ohmstede, ANTONiO "Las dirigencias y sus seguidores, 1811-1816" en MaRta Terán y José Antonio Serrano Ortega, Las guerras de independencia en la América Española, Morelia, El Colegio de Michoacán/Comisión Nacional de Ciencia y Tecnología/ Instituto Nacional de Antropología e Historia/Universidad Michoacana de San Nicolás de Hidalgo, 2002, pp. 217-236.

Garza, Mercedes de LA, "Uso ritual de plantas psicoactivas entre los nahuas y los mayas" en Yólotl GonzÁlez Torres (coord.), Animales y plantas en la cosmovisión mesoamericana, México, Consejo Nacional para la Cultura y las Artes/Instituto Nacional de Antropología e Historia/Plaza y Valdés/Sociedad Mexicana para el Estudio de las Religiones, 2001, pp. 89-104.

GonzÁlez Gómez, Carmen I., El tabaco virreinal. Monopolio de una costumbre, Querétaro, Universidad Autónoma de Querétaro/Fondo Editorial de Querétaro, 2002.

Humboldt, Alejandro, Ensayo político sobre el reino de la Nueva España, París, Casa de Rosa, 1822, 2 vols.

Klein, Herbert S., "La economía de la Nueva España, 1680-1809. Un análisis a partir de las Cajas Reales", Historia Mexicana, El Colegio de México, vol. 34, núm. 4, 1985, pp. 561-609.

Kourí, Emilio, A Pueblo Divided: Business, Property, and Community in Papantla, Mexico, Stanford, Stanford University Press, 2004.

Marchena Fernández, Juan, Oficiales y soldados en el ejército en América, Sevilla, Escuela de Estudios Hispanoamericanos de Sevilla, 1983.

Marichal Salinas, CARlos, La bancarrota del virreinato. Nueva España y las finanzas del Imperio español, 1780-1810, México, Fondo de Cultura Económica, 1999.

McWatters, David Lorne, "The Royal Tobacco Monopoly in Bourbon Mexico, 1764-1810", tesis de doctorado, Estados Unidos de Norteamérica, Universidad de Florida, 1979.

Menegus Bornemann, Margarita (comp.), El repartimiento forzoso de mercancías en México, Perú y Filipinas, México, Instituto de Investigaciones Dr. José María Luis Mora/Centro de Estudios sobre la Universidad-Universidad Nacional Autónoma de México, 2000.

OuWENEEL, ARIJ, "El gobernador de indios, el repartimiento de comercios y la caja de comunidad en los pueblos de indios del México central (siglo XVIII)" en MARgarita Menegus Bornemann (comp.), El repartimiento forzoso de mercancías en México, Perú y Filipinas, México, Instituto de Investigaciones Dr. José María Luis Mora/Centro de Estudios sobre la Universidad-Universidad Nacional Autónoma de México, 2000, pp. 65-97.

PASTOR, RODOLFO, "El repartimiento de mercancías y los alcaldes mayores novohispanos: un sistema de explotación, de sus orígenes a la crisis de 1810” en WoOdRow 
BORAH, El gobierno provincial de la Nueva España 1570-1787, México, Universidad Nacional Autónoma de México, 1985, pp. 201-236.

Pietschmann, Horst, Mexiko swischen Reform un Revolution. Vom bourbonischen Zeitalter zur Unabhängigkeit, Stuttgart, Franz Steiner Verlag Stuttgart, 2000.

Rivera, Juan Carlos y Efraín Castro Morales, "El real estanco del tabaco de la Nueva España" en MARIa CONCEPCiÓn AMERLincK et al., Historia y cultura del tabaco en México, México, Secretaría de Agricultura y Recursos Hidráulicos/Tabacos Mexicanos, 1988, pp. 105-126.

Velázquez Hernández, Emilia, Cuando los arrieros perdieron sus caminos: la conformación regional del Totonacapan, Zamora, El Colegio de Michoacán, 1995.

Villaseñor y SANCHEZ, José ANTONio, Theatro Americano: descripción general de los reinos y provincias de la Nueva España y sus jurisdicciones, México, Imprenta de la viuda de don José Bernardo de Hogal, 1746. 